\title{
The Moderation Effect of Generation on the Relationship between Psychological Flexibility and Covid-19 Preventive Behaviour among Females
}

\author{
Ibolya Kotta $^{1,2}$, Kinga Szabo ${ }^{1,2}$, Eszter Eniko Marschalko ${ }^{1,2}$, Susana Jancso-Farcas ${ }^{1,2}$, \\ Kinga Kalcza-Janosi ${ }^{1,2}$ \\ ${ }^{1}$ BBabes-Bolyai University, Faculty of Psychology and Educational Sciences, Department of Applied \\ Psychology, Cluj-Napoca, Romania \\ ${ }^{2}$ All authors have contributed equally.
}

\begin{abstract}
Disease prevention behaviour is essential during the ongoing COVID-19 pandemic. How people respond to information and regulations to control this infectious disease, could be influenced by their age and generational identity. An individual with an optimal level of psychological flexibility can adapt to challenging situations more efficiently. Hence, the purpose of the present study was to investigate the moderating effect of generation on the relationship between psychological flexibility and Covid-19 preventive behaviour among different generational cohorts of women (baby boomers, X, Y and Z). Data were collected through an online survey. The responses of 834 Hungarian speaking women, aged between 18 and 75 years old, were successfully gathered. The moderation effect was calculated using the PROCESS macro in SPSS. A statistically significant moderation effect of generation was found on the relationship between psychological flexibility and COVID-19 prevention behaviour and the interaction added a small, but significant contribution to the final model predicting preventive behaviour. In Generation Z, psychological flexibility predicted an increase in preventive behaviour, but no significant prediction was found among other generational cohorts. Females in their twenties seemed to be more engaged in COVID-19 prevention behaviour, if their psychological flexibility was higher, but failed to comply with health recommendations and safety protocols at low levels of flexibility. This study may provide a new perspective on how generational cohorts can influence the effect of psychological factors on Covid-19 preventive behaviour.
\end{abstract}

Keywords: pandemic; mental health; adaptation to change; health regulations; generational identity

\section{Introduction}

Since the World Health Organization officially declared the COVID-19 a pandemic (WHO, 11th of March, 2020), multiple health guidelines were imposed by governments. Still ongoing, some countries prepare for the second lockdown trying to protect their citizens. The northern hemisphere of the world seems to be the most affected by the COVID-19 health threat (WHO, 23th of October, 2020). Individual prevention behaviour remains the first line of epidemiological control. The coronavirus caused a systematic chain reaction around the world 


\section{8-20 December, 2020}

\section{Oxford, United Kingdom}

\section{$11^{\text {th }}$ International Conference on Humanities, Psychology \& Social Sciences}

(Chakraborty \& Maity, 2020) and had an enormous impact on workforce, education, including on the daily routines of people. The adherence to health maintenance guidelines is influenced by numerous psychological factors. One of them is risk perception. Individual risk perception is tied to the utilization of prevention techniques, which can stop the spread of the virus (Dryhurst et al., 2020). The results of the study led by Mulia (2019) demonstrated a diversity in risk perception of COVID-19 between different generations. According to Morgan et al. (2019) higher perceived risk was found in the older participants. CDC (The Centers for Disease Control and Prevention) reports also highlighted generational differences, stating that individuals above 65 years are in serious danger of severe health-related complications (CDC, 2020). Prevention behaviour is more decidedly adopted by the baby boomers, while millennials are more disengaged (Cherry \& Morin, 2020).

The additional impact of the uncertain and unpredictable new environment created by the COVID-19 pandemic increased levels of distress in individuals, as reported in several studies from different countries. Many psychological researches focused on possible protective factors of mental health, therefore pinpointed the significant health sustaining role of psychological flexibility during the COVID-19 pandemic. Pakenham et al (2020) found that psychological flexibility increased the resilience throughout the Covid-19 lockdown and supported mental health. Another recent study found that psychological flexibility moderated the relationship between social isolation and mental health outcomes, buffering the negative impact of isolation on distress (Smith et al., 2020). Interventions in psychological flexibility gained empirical support in addressing mental health problems caused by the COVID-19 pandemic (Polizzi et al., 2020; Presti et al., 2020; Landi et al, 2020). Dawson \& Golijani-Moghaddam (2020) evinced that psychological flexibility contributed to more adjusted individual coping strategies related to the Covid-19 pandemic, consequently it may promote better long-term adjustment. This study highlighted that the flexibility, if present, helped individuals in choosing better strategies of personal adjustment and lowered the chance of mental health problems. The authors argued that psychological flexibility was not a coping mechanism, but rather served an important function of selecting and adjusting coping strategies.

Psychological flexibility can be described as a crucial pillar of health and serves a meaningful role in accommodation to challenging circumstances (Kashdan \& Rottenberg, 2010; Gloster et al., 2017). In the past, successful public health strategies were based on the development of psychological flexibility (Fledderus et al, 2011). Psychological flexibility was a significant predictor of sustainable health behaviours (Cheung and Mak, 2016) and positively influenced mental health in chronic diseases like HIV (Landstra, Ciarrochi, Deane, Hillman, 2013). In addition, psychological flexibility enhances quality of life in individuals struggling with chronic pain, on account of lowering the chances of depression and anxiety (McCracken \& Vowles, 2007; McCracken, 2013). Furthermore, long term health supporting behaviours are fostered by psychological flexibility (Cativelli et al., 2018). Moreover, physically active individuals have a higher psychological flexibility than the less physically active individuals (Kangasniemi et al., 2014).

Previous research suggests that psychological flexibility is evenly essential in young and elderly people. Quality of life in the third age and better emotional regulation is facilitated by higher flexibility (Butler \& Ciarrochi, 2007). Emotional wellbeing of young adults was predicted by psychological flexibility in several studies (Masuda et al., 2010; Bond and Bunce, 2003; Bond \& Flaxman, 2006). Additionally, emotional wellbeing is sustained by psychological flexibility (Forman et al., 2007). Lower psychological flexibility has been found to predict trauma and mental health problems in the context of natural disasters, school 


\section{8-20 December, 2020}

\section{Oxford, United Kingdom}

\section{$11^{\text {th }}$ International Conference on Humanities, Psychology \& Social Sciences}

shootings, and violent crimes (e.g., Gold et al., 2007; Kumpula et al., 2011; Marshall and Brockman, 2016). Research in epidemiological events (e.g. SARS) previously evinced the association of pandemics with psychological distress, anxiety and depression (Hawryluck et al., 2004; Taylor, 2020).

\subsection{Objectives}

The aim of the current study was to explore the relationship between psychological flexibility and COVID-19 prevention behaviour, taking into consideration the participants' age and generational identity. This relationship was rarely addressed in the literature, which is what inspired this study.

\section{Method}

\subsection{Participants}

The sample consisted of ethnic Hungarian female participants from several European countries. Four generational cohorts were represented in the sample population: baby boomers (age > 56), X (age 41-55), Y (age 24-40) and Z (age 18-25). Sample characteristics stratified by generational cohorts are presented in Table 1. In terms of residency, educational level and marital status, the sample was heterogeneous. Generational distributions were made based on Meretei's (2017) age threshold, which takes into account differences between Central Europe and other regions. This allotment resulted in: baby boomers - born between 1946 and 1964, Gen X - born between 1965 to 1979, Gen Y or millennials - born between 1980 and 1995, and the Gen Z - born after 1995.

At the time of data collection and measurement, less than $15 \%$ of participants from all generational cohorts declared having acquaintances infected with Covid-19.

Table 1. Sociodemographic data of the participants stratified by generational status (Total N=834)

\begin{tabular}{|c|c|c|c|c|c|}
\hline & & $\begin{array}{l}\text { Baby boomers } \\
(\mathbf{n}=\mathbf{2 3 0})\end{array}$ & $\begin{array}{l}\text { Gen X } \\
(n=356)\end{array}$ & $\begin{array}{l}\text { Gen Y } \\
(n=163)\end{array}$ & $\begin{array}{l}\text { Gen Z } \\
(n=85)\end{array}$ \\
\hline \multicolumn{2}{|l|}{ Age $(M \pm S D)$} & $62.30(4.66)$ & $48.12(4.29)$ & $34.73(4.47)$ & $20.51(1.94)$ \\
\hline Gender & Female & $230(100 \%)$ & $356(100 \%)$ & $163(100 \%)$ & $85(100 \%)$ \\
\hline \multirow[t]{5}{*}{ Educational level } & $\begin{array}{l}8 \text { grades/Grade } 8 \text { or } \\
\text { less }\end{array}$ & $1(.4 \%)$ & $2(.6 \%)$ & - & - \\
\hline & Baccalaureate & $60(26.1 \%)$ & $108(30.3 \%)$ & $28(17.2 \%)$ & $2(2.4 \%)$ \\
\hline & College, university & $149(64.8 \%)$ & $210(59.0 \%)$ & $101(62.0 \%)$ & $42(49.4 \%)$ \\
\hline & Master's degree & $13(5.7 \%)$ & $23(6.5 \%)$ & $26(16.0 \%)$ & $39(45.9 \%)$ \\
\hline & Doctor's degree & $7(3.0 \%)$ & $13(3.7 \%)$ & $8(4.9 \%)$ & $1(1.2 \%)$ \\
\hline \multirow[t]{5}{*}{ Country } & Hungary & $221(96.1 \%)$ & $324(91.0 \%)$ & $114(69.9 \%)$ & $13(15.3 \%)$ \\
\hline & Romania & $6(2.6 \%)$ & $21(5.9 \%)$ & $40(24.5 \%)$ & $72(84.7 \%)$ \\
\hline & Germany & $1(.4 \%)$ & $2(.6 \%)$ & $1(.6 \%)$ & - \\
\hline & Ireland & - & $2(.6 \%)$ & - & - \\
\hline & Sweden & - & - & $4(2.5 \%)$ & - \\
\hline
\end{tabular}


18-20 December, 2020

Oxford, United Kingdom $11^{\text {th }}$ International Conference on Humanities, Psychology \& Social Sciences

\begin{tabular}{llllll} 
& England & - & $2(.6 \%)$ & $1(.6 \%)$ & - \\
& Other & $2(.9 \%)$ & $5(1.4 \%)$ & $3(1.8 \%)$ & - \\
\hline Residency & Capital city & $57(24.8 \%)$ & $88(24.7 \%)$ & $38(23.3 \%)$ & $3(3.5 \%)$ \\
& City & $136(59.1 \%)$ & $186(52.2 \%)$ & $83(50.9 \%)$ & $54(63.5 \%)$ \\
& Village & $37(16.1 \%)$ & $82(23.0 \%)$ & $42(25.8 \%)$ & $28(32.9 \%)$ \\
\hline Marital status & Single & $25(10.9 \%)$ & $48(13.5 \%)$ & $34(20.9 \%)$ & $36(42.4 \%)$ \\
& Living Together & $24(10.4 \%)$ & $56(15.7 \%)$ & $43(26.4 \%)$ & $45(52.9 \%)$ \\
& Married & $111(48.3 \%)$ & $192(53.9 \%)$ & $73(44.8 \%)$ & $2(2.4 \%)$ \\
& Divorced & $51(22.2 \%)$ & $57(16.0 \%)$ & $11(6.7 \%)$ & - \\
\hline $\begin{array}{l}\text { Infected } \\
\text { acquaintances }\end{array}$ & Other & $19(8.3 \%)$ & $3(.8 \%)$ & $2(1.2 \%)$ & $2(2.4 \%)$ \\
\hline $\begin{array}{l}\text { Psychological } \\
\text { flexibility }\end{array}$ & Yes & $31(13.5 \%)$ & $47(13.2 \%)$ & $24(14.7 \%)$ & $8(9.4 \%)$ \\
$\begin{array}{l}\text { Covid-19 } \\
\text { preventive } \\
\text { behaviours }\end{array}$ & & $25.19(3.04)$ & $25.00(2.97)$ & $24.64(3.10)$ & $23.56(3.31)$ \\
\hline
\end{tabular}

\subsection{Instruments}

Psychological flexibility. The predictor variable was measured on a scale developed by BenItzhak, Bluvstein and Maor (2014) that assesses five dimensions of psychological flexibility: positive perception of change (PPC), characterization of the self as flexible (FS), characterization of the self as open and innovative (OS), perception of reality as dynamic and changing (DR), and a perception of reality as multifaceted (MR). The 18 items were rated on a 6-point scale from 1 (not agree at all) to 5 (totally agree). This instrument showed a high internal reliability of the total scale, Cronbach's $\alpha=.918$.

Covid-19 preventive behaviour. The outcome variable of the analysis was assessed using an 18-item questionnaire, inspired by previous research on other pandemic outbreaks (ex. Cheng $\& \mathrm{Ng}, 2006)$ and the WHO prevention recommendations (WHO, 2019). The items were rated on a 4-point scale from 1 (very unlikely) to 4 (very likely). Total score was computed from subscale means (range 4-16). Higher scores suggest greater engagement in preventive behaviour. This instrument showed a high internal reliability, Cronbach's $\alpha=.801$.

\subsection{Procedure}

Participants were recruited online in April 2020. First, informed consent was obtained and anonymity was assured, then demographic data was collected and participants were asked to provide information concerning their age in order to assign them to a generational cohort. Finally, the scales were completed.

\subsection{Data analysis}

In order to set the sample size to be suitable for detecting small effect sizes, an a priori power analysis via G*Power3 (Faul, Erdfelder, Lang, \& Buchner, 2007) for multiple linear regression was performed. 


\section{8-20 December, 2020}

\section{Oxford, United Kingdom}

\section{$11^{\text {th }}$ International Conference on Humanities, Psychology \& Social Sciences}

A data cleaning analysis was conducted on the initial data set based on Tabachnick \& Fidell's (2013) work. Outliers and missing values were excluded from the data analysis.

Descriptive statistics, namely percentages for categorical variables and mean and standard deviations for continuous variables were provided. The internal consistency of scales and subscales was assessed by calculating Cronbach alpha's reliability values.

The moderation analysis was conducted using the Process macro (Model 1) in SPSS version 23.0 Program. The outcome variable for analysis was preventive behaviours against COVID19 (continuous variable). The predictor variable for the analysis was psychological flexibility (continuous variable), while generation served as a categorical moderator in the model.

Preliminary analyses were carried out to insure against the violation of the assumptions of the normality of the standardized residuals, linearity, multicollinearity and homoscedasticity. No missing data were detected. The predictor psychological flexibility was mean centred to treat the issues of multicollinearity. For the multi-categorical moderator, the indicator coding system was applied, and baby boomer's generation was set as the reference group.

\section{Results}

The a priori power analysis for multiple linear regression based on type I error of .05 and statistical power .80 showed that for a medium effect size $\left(f^{2}=.15\right)$ the required sample size is $\mathrm{n}=77$, while for a small effect size $\left(f^{2}=.02\right)$ the required sample size is $\mathrm{n}=550$. Thus, the sample of the present study $(\mathrm{N}=834)$ is suitable for detecting small effect sizes.

The descriptive statistics of the variables are summarized in Table 2.

Table 2. Descriptive statistics and bivariate correlations of the research variables

\begin{tabular}{crllllll}
\hline $\begin{array}{c}\text { Researc } \\
\text { h variable }\end{array}$ & $\begin{array}{c}\text { Mean } \pm \text { SD } \\
\text { Frequency (\%) }\end{array}$ & Min. & Max. & Skewness & Kurtosis & PF & PB \\
\hline PF & $24.84 \pm 3.08$ & $\begin{array}{l}15.2 \\
7\end{array}$ & $\begin{array}{l}30.0 \\
0\end{array}$ & -.415 & -.437 & - & $.093^{*}$ \\
PB & $11.77 \pm 1.75$ & $\begin{array}{l}6.13 \\
\text { T. }\end{array}$ & $\begin{array}{l}15.6 \\
0\end{array}$ & -.253 & -.264 & - & - \\
\hline
\end{tabular}

Notes. ** $\mathrm{p}<.001$, two-tailed, $P B=$ Preventive Behaviour, $P F=$ Psychological Flexibility

The overall model $F(7,826)=5.24, p<.001, R^{2}=.04$ was significant. Differences in preventive behaviour based on generational cohorts were found, namely, participants from the baby boomer cohort declared a significantly higher rate of preventive health maintenance behaviour as compared to Gen $\mathrm{X}$ and $\mathrm{Y}$. The difference in preventive behaviour between baby boomers and Gen $\mathrm{Z}$ was not significant (see Table 3 ).

Psychological flexibility $b=.004, t(826)=.117, p=.90$ was not predictive of preventive behaviour. Table 3 presents the association between psychological flexibility and preventive behaviour between generations.

Table 3. Interaction effect between generation and psychological flexibility predicting Covid-19 preventive behaviour 


\begin{tabular}{|c|c|c|c|c|c|c|c|}
\hline $\begin{array}{l}\text { Outcome } \\
\text { variable }\end{array}$ & Predictor & $b$ & S.E. & $t$ & $p$ & LLCI & ULCI \\
\hline \multicolumn{8}{|l|}{$\begin{array}{l}\text { Preventive } \\
\text { behaviour }\end{array}$} \\
\hline & $\mathrm{PF}$ & .004 & .037 & .117 & .90 & -.069 & .078 \\
\hline & W1 & -.572 & .146 & -3.905 & $1^{.00}$ & -.859 & -.284 \\
\hline & W2 & -.553 & .177 & -3.121 & $2^{.00}$ & -.900 & -.205 \\
\hline & W3 & -.214 & .231 & -.926 & $5^{.35}$ & -.666 & .239 \\
\hline & $\mathrm{PF} * \mathrm{~W} 1$ & .014 & .048 & .294 & $9^{.76}$ & -.081 & .109 \\
\hline & $\mathrm{PF} * \mathrm{~W} 2$ & .058 & .057 & 1.013 & $1^{.31}$ & -.054 & .171 \\
\hline & $\mathrm{PF} * \mathrm{~W} 3$ & .226 & .068 & 3.331 & $1^{.00}$ & .093 & .360 \\
\hline $\mathrm{R}^{2}$ & .04 & & & & & & \\
\hline
\end{tabular}

Note. $b=$ unstandardized coefficient, S.E. $=$ standard error, 95\% CI. The scores for PF are mean centred. $L L C I=$ lower limit confidence interval, $U L C I=$ upper limit confidence interval, $P B=$ Preventive Behaviour, $P F=$ Psychological Flexibility, $W 1=$ Comparing Gen $B B$ and $X$ on $P B, W 2=$ Comparing Gen $B B$ and $Y$, $W 3=$ Comparing Gen $B B$ and $Z$.

A significant interaction was found for baby boomers and Gen $\mathrm{Z}$ by psychological flexibility $b=.22, t(826)=3.33, p<.001$. No interaction was found for baby boomers and Gen $\mathrm{X}$, respectively baby boomers and Gen Y on psychological flexibility (see Table 3 ). Figure 1 plots the interaction effect between psychological flexibility and generational cohorts on preventive behaviours of Covid-19.

Figure 1. The relationship between psychological flexibility and preventive behaviour moderated by generation 
18-20 December, 2020

Oxford, United Kingdom

\section{$11^{\text {th }}$ International Conference on Humanities, Psychology \& Social Sciences}

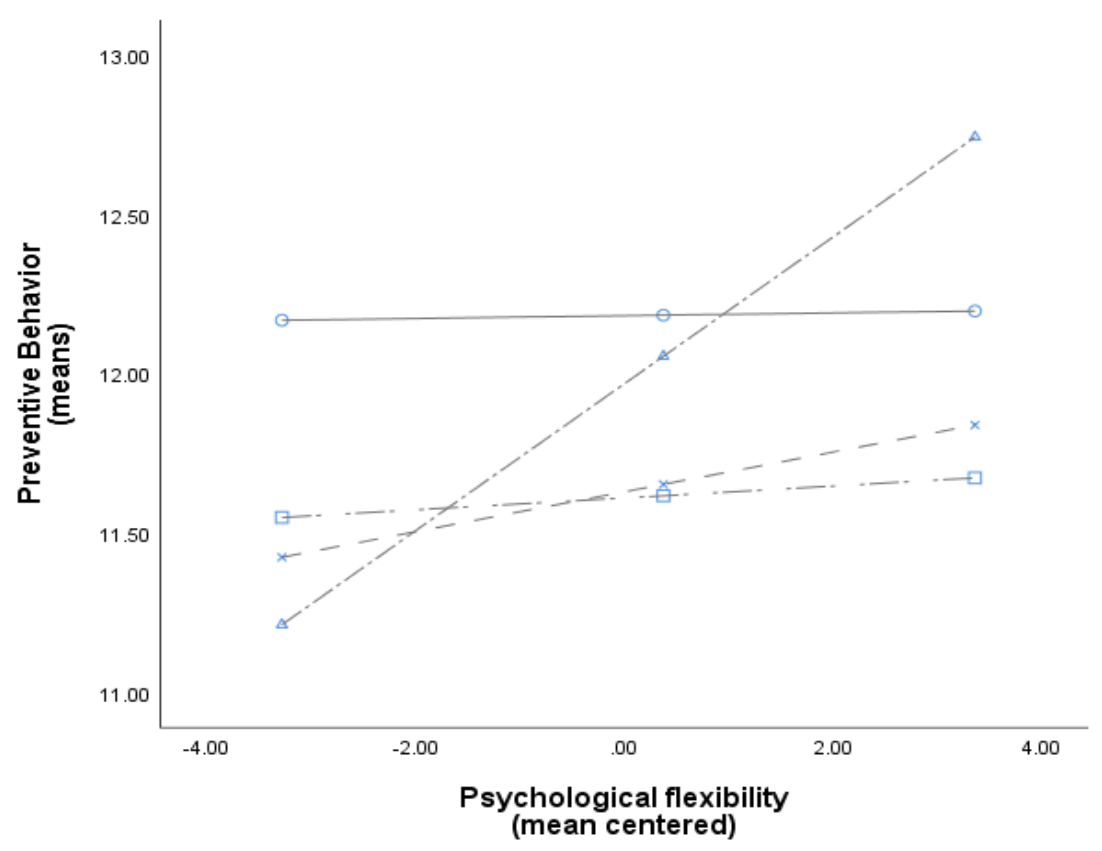

Generation

Baby Boomer

$X$

$<$
$Z$

The interaction significantly added a total of $1.5 \%$ to the overall $\mathrm{R} 2$ of the model, $F(3,826)=$ $4.253, p=.005$.

Next, simple slopes for psychological flexibility to preventive behaviour on different levels of the moderator were examined. Results showed that psychological flexibility significantly predicted preventive behaviour only for Gen $\mathrm{Z}, b=.23, t(826)=4.067, p=.001$. The prediction was not significant for baby boomers, Gen $\mathrm{X}$ and $\mathrm{Y}$. Table 4 shows the simple slopes for all four levels of the moderator variable.

Table 4. Simple slopes: conditional effects of psychological flexibility at values of generation

\begin{tabular}{cllllll}
\hline Generation & $\mathbf{b}$ & S.E. & $\mathbf{t}$ & $\mathbf{p}$ & LLCI & ULCI \\
\hline $\mathbf{B B}$ & .004 & .037 & .117 & .907 & -.069 & .078 \\
$\mathbf{X}$ & .019 & .031 & .605 & .545 & -.042 & .079 \\
$\mathbf{Y}$ & .063 & .044 & 1.436 & .151 & -.023 & .148 \\
$\mathbf{Z}$ & .231 & .057 & 4.067 & .000 & .119 & .342 \\
\hline
\end{tabular}

In other words, the relation between psychological flexibility and a higher commitment to maintain health preventive behaviours against COVID-19 depended on belonging to Gen $\mathrm{Z}$.

\section{Discussion and conclusions}

In this study a significant, but small moderation effect of the generational identity was found on the relationship between psychological flexibility and prevention behaviour. In what concerns the youngest females (Gen Z), when psychological flexibility was higher, then the Covid-19 prevention behaviour was better. In none of the other cases (baby boomers, Gen X, Gen Y) was this effect significant. Age-related differences in Covid-19 prevention were described in several studies (Morgan et al, 2019; Mulia et al., 2019; Cherry \& Morin, 2020), 


\section{8-20 December, 2020}

\section{Oxford, United Kingdom}

\section{$11^{\text {th }}$ International Conference on Humanities, Psychology \& Social Sciences}

but the cause was usually linked to risk perception (Dryhurst et al., 2020). The role played by psychological flexibility dependent on age or generational identity is less addressed. Reed, Chan, \& Mikels (2014) showed that older adults express a positivity bias compared to younger adults in decision-making (for a review, see Reed, Chan, \& Mikels, 2014), which can influence them in choice situations moderated by psychological flexibility, as well (Steenhaut et al., 2020). Meanwhile, limited information is available about age related positive biases associated with health outcomes and viral threats. Literature mostly suggests that psychological flexibility plays a protective role in mental health and in personal resilience, regardless of age, during the Covid-19 pandemic (Polizzi et al., 2020; Presti et al., 2020; Landi et al., 2020). Recent studies evinced that psychological flexibility is a protective factor favouring psychological resilience (Pakenham et al., 2020) and it buffers the negative impact of social distancing (Smith et al., 2020). Accordingly, the health of elderly and young people, can as well be protected (Butler \& Ciarrochi, 2007; Masuda et al., 2010; Forman et al., 2007) and healthier lifestyle habits can be sustained (Cativelli et al., 2018), assuming they are more psychologically flexible.

The results of the current study interpreted in the ongoing context of a pandemic add another significance to generational identity, which favours youth, with regard to the prevention of COVID-19 transmission. It is difficult to argue for an explanation, since this outcome was not previously documented in research data from former epidemic events. At the root of this difference in effects could be the conceptualization of psychological flexibility. Another explanation could be ascribed to the diverse, intergenerational interpretations of undesirable circumstances or illness. The relationship between prevention behaviour and psychological flexibility is rarely analysed in the literature and the results usually pinpoint to the positive impact of psychological flexibility on sustaining health protective behaviours (Cheung \& Mak, 2016, Cativelli et al., 2018), but there is little known about the influence of this construct on controlling the spread of an infectious disease through individual health behaviours. Psychological flexibility is having a decisive role in opting for coping strategies, but it cannot be viewed as a coping mechanism itself (Nielsen et al., 2016; Dawson \& Golijani-Moghaddam, 2020). It was also found that psychological flexibility and COVID-19 outcomes were only partly-mediated by coping responses to the COVID-19 (Dawson \& Golijani-Moghaddam, 2020). Prevention of avoidance behaviours and facilitation of acceptance is definitory for psychologically flexible behaviours, while disease avoidance is crucial in prevention behaviour of COVID-19. Psychological flexibility in the adjustment to the COVID-19 pandemic requires for a deliberate appliance of avoidance. The present study's results showed that when women from Generation $\mathrm{Z}$ had higher psychological flexibility, they tended to use more strategies of avoidance in Covid-19 prevention, than the older generations. Further research is needed to clarify our findings.

\subsection{Limitations and future directions}

In the current study, the targeted constructs were assessed by self-reported measures, therefore the risk of bias in interpretation can be considered high. The study was cross-sectional, and the dynamics in COVID-19 prevention behaviour could not be analysed. Participants were recruited online, randomly, without any control or previous assessment of psychological wellbeing. Considering that there is a lack of studies focused on age related positive or negative biases regarding health outcomes and viral threats, we consider this approach to be a very important future research topic. Furthermore, the construct of psychological flexibility could be affected by generational identity, and this could be addressed theoretically and in research 
18-20 December, 2020

Oxford, United Kingdom

\section{$11^{\text {th }}$ International Conference on Humanities, Psychology \& Social Sciences}

to further clarify the present findings. Cultural moderation could be tested employing a cross cultural perspective.

\section{Ethics Statement}

The study is in line with research ethics and data collection was approved by the Ethics Committee of the University of Babeș-Bolyai (RO) (reference number 6075/23.04.2020).

\section{Acknowledgement}

The publication of this article was supported by the 2020 Development Fund of the Babes-Bolyai University.

\section{References}

Ben-Itzhak, S., Bluvstein, I., Maor, M. (2014). The Psychological Flexibility Questionnaire (PFQ): Development, Reliability and Validity. WebmedCentral Psychology 5(4):WMC004606, 1-10.

Bond, F.W., Bunce, D. (2003). The role of acceptance and job control in mental health, job satisfaction, and work performance. J Appl Psychol. 88(6):1057-1067.

Bond, F.W., \& Flaxman, P.E. (2006). The Ability of Psychological Flexibility and Job Control to Predict Learning, Job Performance, and Mental Health. Journal of Organizational Behavior Management, 26(1-2), 113-130. https://doi.org/10.1300/j075v26n01_05

Butler, J., \& Ciarrochi, J. (2007). Psychological acceptance and quality of life in the elderly. Quality of Life Research, 16(4), 607-615. https://doi.org/10.1007/s11136-006-9149-1

Cattivelli, R., Castelnuovo, G., Musetti, A., Varallo, G., Spatola, C. A. M., Riboni, F. V., Usubini, A. G., Tosolin, F., Manzoni, G. M., Capodaglio, P., Rossi, A., Pietrabissa, G., \& Molinari, E. (2018). ACTonHEALTH study protocol: promoting psychological flexibility with activity tracker and mHealth tools to foster healthful lifestyle for obesity and other chronic health conditions. Trials, 19(1). https://doi.org/10.1186/s13063-018-2968-X

Centers for Disease Control and Prevention (2020). Coronavirus Disease 2019 (COVID-

19).CDC. https://www.cdc.gov/coronavirus/2019-ncov/need-extra-precautions/peoplewith-medical-

conditions.html?CDC_AA_refVal=https\%3A\%2F\%2Fwww.cdc.gov\%2Fcoronavirus\% 2F2019-ncov\%2Fneed-extra-precautions\%2Fgroups-at-higher-risk.html [Accessed February 11, 2020]

Chakraborty, I., and Maity, P. (2020). COVID-19 outbreak: Migration, effects on society, global environment and prevention. Science of The Total Environment, 728: 138882. https://doi.org/10.1016/j.scitotenv.2020.138882

Cheng, C., Ng, A.-K. (2006). Psychosocial Factors Predicting SARS-Preventive Behaviors in Four Major SARS-Affected Regions. Journal of Applied Social Psychology, 36, 1, 222-247. https://doi.org/10.1111/j.0021-9029.2006.00059.x 


\section{8-20 December, 2020}

\section{Oxford, United Kingdom}

\section{$11^{\text {th }}$ International Conference on Humanities, Psychology \& Social Sciences}

Cherry, K., and Morin, A. (2020). How Different Generations Are Responding to COVID-19. (n.d.). Verywell Mind. https://www.verywellmind.com/how-different-generationsare-responding-to-covid-19-4802517 [Accessed August 3, 2020]

Cheung, K. W., and Mak, Y. W. (2016). Association between Psychological Flexibility and Health Beliefs in the Uptake of Influenza Vaccination among People with Chronic Respiratory Diseases in Hong Kong, International Journal of Environmental Research and Public Health, 13:155, 1-14. https://doi.org/10.3390/ijerph13020155

Dawson, D. L., \& Golijani-Moghaddam, N. (2020). COVID-19: Psychological flexibility, coping, mental health, and wellbeing in the UK during the pandemic. Journal of Contextual Behavioral Science, 17, 126-134. https://doi.org/10.1016/j.jcbs.2020.07.010

Dryhurst, S., Schneider, C., Kerr, J., Freeman, A., Recchia, G., van der Bles, Spiegelhalter, D., and van der Linden, S. (2020). Risk perceptions of COVID-19 around the world. Journal Of Risk Research, 1-13._https://doi.org/10.1080/13669877.2020.1758193

Faul, F., Erdfelder, E., Lang, A., \& Buchner, A. (2007). G*Power 3: A flexible statistical power analysis program for the social, behavioral, and biomedical sciences. Behavior Research Methods, 39, 175-191._https://doi.org/10.3758/BF03193146

Fledderus, M., Bohlmeijer, E. T., Smit, F., \& Westerhof, G. J. (2010). Mental Health Promotion as a New Goal in Public Mental Health Care: A Randomized Controlled Trial of an Intervention Enhancing Psychological Flexibility. American Journal of Public Health, 100(12), 2372-2372. https://doi.org/10.2105/ajph.2010.196196

Forman, E. M., Herbert, J. D., Moitra, E., Yeomans, P. D., \& Geller, P. A. (2007). A randomized controlled effectiveness trial of acceptance and commitment therapy and cognitive therapy for anxiety and depression. Behavior Modification, 31(6), 772-799. https://doi.org/10.1177/0145445507302202

Gloster, A. T., Meyer, A. H., \& Lieb, R. (2017). Psychological flexibility as a malleable public health target: Evidence from a representative sample. Journal of Contextual Behavioral Science, 6(2), 166-171. https://doi.org/10.1016/j.jcbs.2017.02.003

Gold, S. D., Marx, B. P., \& Lexington, J. M. (2007). Gay male sexual assault survivors: The relations among internalized homophobia, experiential avoidance, and psychological symptom severity. Behaviour Research and Therapy, 45(3), 549-562. https://doi.org/10.1016/j.brat.2006.05.006

Hawryluck L, Gold WL, Robinson S, Pogorski S, Galea S, Styra R. SARS control and psychological effects of quarantine, Toronto, Canada. Emerg Infect Dis. 2004 Jul;10(7):1206-12. https://doi.org/10.3201/eid1007.030703.

Kangasniemi, A., Lappalainen, R., Kankaanpää, A., \& Tammelin, T. (2014). Mindfulness skills, psychological flexibility, and psychological symptoms among physically less active and active adults. Mental Health and Physical Activity, 7(3), 121-127. https://doi.org/10.1016/j.mhpa.2014.06.005

Kashdan, T. B., \& Rottenberg, J. (2010). Psychological flexibility as a fundamental aspect of health. Clinical Psychology Review, 30(7), 865-878. https://doi.org/10.1016/j.cpr.2010.03.001 


\section{8-20 December, 2020}

\section{Oxford, United Kingdom}

\section{$11^{\text {th }}$ International Conference on Humanities, Psychology \& Social Sciences}

Kumpula, M. J., Orcutt, H. K., Bardeen, J. R., \& Varkovitzky, R. L. (2011). Peritraumatic dissociation and experiential avoidance as prospective predictors of posttraumatic stress symptoms. Journal of Abnormal Psychology, 120(3), 617-627. https://doi.org/10.1037/a0023927

Landi, F., Barillaro, C., Bellieni, A., Brandi, V., Carfî, A., D'Angelo, M., Fusco, D., Landi, G., Lo Monaco, R., Martone, A. M., Marzetti, E., Pagano, F., Pais, C., Russo, A., Salini, S., Tosato, M., Tummolo, A., Benvenuto, F., Bramato, G., Catalano, L., ... and Bernabei, R. (2020). The New Challenge of Geriatrics: Saving Frail Older People from the SARS-COV-2 Pandemic Infection. The journal of nutrition, health \& aging, 24(5), 466-470. https://doi.org/10.1007/s12603-020-1356-X

Landstra, J.B., Ciarrochi. J., Deane, F. P., and R.J. Hillman (2013). Identifying and Describing Feelings and Psychological Flexibility Predict Mental Health in Men with HIV. British Journal of Health Psychology, 18 (4), 844-857. https://doi.org/10.1111/bjhp.12026.

Marshall, E.-J., \& Brockman, R. N. (2016). The Relationships Between Psychological Flexibility, Self-Compassion, and Emotional Well-Being. Journal of Cognitive Psychotherapy, 30(1), 60-72. https://doi.org/10.1891/0889-8391.30.1.60

Masuda, A., Price, M., Anderson, P. L., \& Wendell, J. W. (2010). Disordered Eating-Related Cognition and Psychological Flexibility as Predictors of Psychological Health Among College Students. Behavior Modification, 34(1), 3-15. https://doi.org/10.1177/0145445509351569

McCracken, L.M. (2013). Committed Action: An Application of the Psychological Flexibility Model to Activity Patterns in Chronic Pain. The Journal of Pain, 14(8), 828-835. https://doi.org/10.1016/j.jpain.2013.02.009

McCracken, L.M., \& Vowles, K. E. (2007). Psychological Flexibility and Traditional Pain Management Strategies in Relation to Patient Functioning With Chronic Pain: An Examination of a Revised Instrument. The Journal of Pain, 8(9), 700-707. https://doi.org/10.1016/j.jpain.2007.04.008

Mulia, D. (2019). The Differences in Risk Perception between Millennials and Baby Boomers in Online Transactions. Jurnal Manajemen, 23(3), 375. https://doi.org/10.24912/jm.v23i3.570.

Morgan, J., Reidy, J., and Probst, T. (2019). Age Group Differences in Household Accident Risk Perceptions and Intentions to Reduce Hazards. International Journal of Environmental Research and Public Health, 16(12), 2237. https://doi.org/10.3390/ijerph16122237

Nielsen E., Sayal K., Townsend E. (2016). Exploring the relationship between experiential avoidance, coping functions and the recency and frequency of self-harm. PloS One.11(7)

Pakenham, K. I., Landi, G., Boccolini, G., Furlani, A., Grandi, S., \& Tossani, E. (2020). The moderating roles of psychological flexibility and inflexibility on the mental health impacts of COVID-19 pandemic and lockdown in Italy. Journal of Contextual Behavioral Science, 17, 109-118. https://doi.org/10.1016/j.jcbs.2020.07.003 
18-20 December, 2020

Oxford, United Kingdom

\section{$11^{\text {th }}$ International Conference on Humanities, Psychology \& Social Sciences}

Polizzi, C., Lynn, S. J., and Perry, A. (2020). Stress and coping in the time of covid-19: pathways to resilience and recovery. Clin. Neuropsychiatry 17, 59-62. https://doi.org/10.36131/CN20200204

Presti, G., Dal Lago, B., Fattori, A., Mioli, G., Moderato, P., Sciaretta, L. and Costantino, M.A. (2020). Mental health support to staff in a major hospital in Milan (Italy) during the COVID-19 pandemic: a framework of actions. General Psychiatry, 33(4), e100244. https://doi.org/10.1136/gpsych-2020-100244

Reed, A. E., Chan, L., \& Mikels, J. A. (2014). Meta-analysis of the age-related positivity effect: Age differences in preferences for positive over negative information. Psychology and Aging, 29, 1-15. https://doi.org/10.1037/a0035194

Smith, B. M., Twohy, A. J., \& Smith, G. S. (2020). Psychological inflexibility and intolerance of uncertainty moderate the relationship between social isolation and mental health outcomes during COVID-19. Journal of Contextual Behavioral Science, 18, 162-174. https://doi.org/10.1016/j.jcbs.2020.09.005

Steenhaut, P., Rossi, G., Demeyer, I., \& De Raedt, R. (2020). Flexibility as a Mediator between Personality and Well-Being in Older and Younger Adults: Findings from Questionnaire Data and a Behavioral Task. Experimental Aging Research, 46(5), 446468. https://doi.org/10.1080/0361073x.2020.1805935

Tabachnick, B.G., and Fidell, L.S. (2013). Using multivariate statistics, 6th ed. Pearson

Taylor, S. E., Kemeny, M. E., Reed, G. M., Bower, J. E., and Gruenewald, T. L. (2000). Psychological resources, positive illusions, and health. American Psychologist, 55(1), 99-109._https://doi.org/10.1037/0003-066x.55.1

World Health Organization. (2019). Advice for the public. https://www.who.int/emergencies/diseases/novel-coronavirus-2019/advice-for-public [Accessed June 10, 2020]

World Health Organization. Director-General's opening remarks at the media briefing on COVID-19 - 11 March 2020. (2020, March 11). https://www.who.int/dg/speeches/detail/who-director-general-s-opening-remarks-atthe-media-briefing-on-covid-19---11-march-2020_[Accessed September 15, 2020] 